\title{
BMJ Open Relationship between visual acuity and muscle mass in the Korean older population: a cross-sectional study using Korean National Health and Nutrition Examination Survey
}

Ji Hyun Moon (D) ,1,2 Yun Hwan Oh, ${ }^{1,2}$ Mi Hee Kong, ${ }^{1,2}$ Hyeon Ju Kim (D) ${ }^{1,2}$

To cite: Moon JH, $\mathrm{Oh} \mathrm{YH}$, Kong $\mathrm{MH}$, et al. Relationship between visual acuity and muscle mass in the Korean older population: a crosssectional study using Korean National Health and Nutrition Examination Survey. BMJ Open 2019;9:e033846. doi:10.1136/ bmjopen-2019-033846

- Prepublication history for this paper is available online. To view these files, please visit the journal online (http://dx.doi. org/10.1136/bmjopen-2019033846).

Received 24 August 2019 Revised 30 0ctober 2019 Accepted 11 November 2019

Check for updates

(C) Author(s) (or their employer(s)) 2019. Re-use permitted under CC BY-NC. No commercial re-use. See rights and permissions. Published by BMJ.

${ }^{1}$ Department of Family Medicine, Jeju National University Hospital, Jeju, Republic of Korea

${ }^{2}$ Departmanet of Family Medicine, Jeju National University School of Medicine, Jeju, Republic of Korea

Correspondence to

Dr Hyeon Ju Kim;

fmhjukim@hanmail.net

\section{ABSTRACT}

Objectives We aimed to assess the effects of visual acuity on muscle mass, which is an important indicator of health in older populations.

Design Pooled-sample cross-sectional study.

Setting Nationally representative population survey data. Participants The present study analysed men aged 65 years or older who participated in the Korea National Health and Nutrition Examination Survey (KNHANES, 2008-2011).

Primary and secondary outcome measures Muscle mass was measured by dual-energy X-ray absorptiometry scan, and low muscle mass was defined as appendicular skeletal mass divided by height squared $\left(\mathrm{kg} / \mathrm{m}^{2}\right)<6.43 \mathrm{~kg} /$ $\mathrm{m}^{2}$ (lowest quintile of the older population in KNHANES, 2008-2011). Visual acuity was evaluated based on bestcorrected visual acuity of the better eye.

Results Of the 1733 participants, $89.9 \%$ had good visual acuity. After adjusting for age, the height-adjusted appendicular skeletal muscle mass values were 7.16 and $7.00 \mathrm{~kg} / \mathrm{m}^{2}$ in the good and poor vision groups, respectively ( $p=0.042)$. According to our criterion for low muscle mass, the prevalence of low muscle mass was $16.4 \%$ and $34.7 \%$ in the good and poor vision groups, respectively. After adjusting for age, smoking status, alcohol consumption status, frequency of physical activity, educational level, the status of basic livelihood recipient and history of stroke, the poor visual acuity group had higher odds of low muscle mass than the good visual acuity group ( $0 \mathrm{R}=1.60 ; 95 \% \mathrm{Cl} 1.02$ to $2.50 ; \mathrm{p}=0.040$ ). Conclusions Older men with decreased visual acuity have low muscle mass. Poor vision might be an indicator of low muscle mass.

\section{INTRODUCTION}

Impaired visual acuity is a common phenomenon in the older population. This poor vision, which many older people take for granted, is closely linked to geriatric syndrome. In older population, the relationship between decreased visual acuity and increased frequency of falls is well known. ${ }^{1}$ Decreased visual activity is a significant
Strengths and limitations of this study

- This study used nationally representative data with multistage clustered probability design.

- Muscle mass was measured by dual-energy X-ray absorptiometry, which is the most widely used and appropriate method for evaluating body composition.

- The design of this study is cross-sectional, and the causal direction cannot be evaluated.

- In this study, we did not investigate physical functions or visual function items except for visual acuity.

predictor of falls and is closely linked to the tendency for multiple falls. ${ }^{2}$ Furthermore, in older patients with diabetes mellitus, visual impairment was independently associated with the functional disabilities. ${ }^{3}$ Decreased visual function is related to frailty, which can be evaluated using gait speed, grip strength, peak expiratory flow rate and the ability to rise from a chair without arm support. ${ }^{4}$ According to the previous study of China that included 2476 individuals aged 50-74 years with functional presbyopia, near-vision acuity was positively correlated with hand-grip strength. ${ }^{5}$ Moreover, a previous observational study that evaluated lower body strength and power showed that compared with the impaired vision group, age-matched and sexmatched participants with normal vision had significantly greater values of peak torque and mean power in the hamstrings and quadriceps. ${ }^{6}$ Hence, reduced vision in the older population is likely related to reduced muscle strength.

Muscle strength is highly correlated with muscle mass, ${ }^{7}$ and loss of muscle mass is the starting point of frailty, and in the older population, changes in body composition can be easily linked to the risk of various geriatric syndromes. ${ }^{8}$ Muscle mass varies due to 
various causes and can be partially improved by appropriate exercises and sufficient nutrition. ${ }^{9}{ }^{10}$ However, it is not completely understood what affects the reduction in muscle mass and how it can be managed.

We hypothesised that vision, which is related with frailty and strength of muscle, would be closely linked to muscle mass and that poor vision would be an independent risk factor of low muscle mass in men of older population. The purpose of this study was to evaluate the relationship between visual acuity and skeletal muscle mass, a key risk factor for sarcopenia and subsequent geriatric syndrome, in a large older population.

\section{METHODS}

Participants

This study used data from the Korean National Health and Nutrition Examination Survey (KNHANES). The KNHANES is a nationwide survey that has been collected by the Korea Centers for Disease Control and Prevention since 1998; a multistage sampling design was used to stratify household units based on age, sex and geographic areas in order to identify participants from the general Korean population Therefore, the data are representative of the health and nutritional status and health behaviours of the entire population in Korea. The survey is composed of a self-reported questionnaire (ie, a nutritional questionnaire) and health-related measurements that were obtained by trained staff. Dual-energy X-ray absorptiometry (DXA) was performed as one of the health measurements from 2008 to 2011 in participants aged older than 10 years. A detailed description of the study is provided elsewhere. ${ }^{11}$ The present study analysed men aged 65 years or older who participated in the KNHANES survey (between 2008 and 2011) and who underwent a health interview as well as health measurements including the DXA scan. After excluding individuals with glaucoma, cataract, macular degeneration and any eventual malignancy, the study comprised 1733 men.

\section{Measures of vision}

Participants' visual acuity was measured with and without their glasses at a $4 \mathrm{~m}$ distance using Jin's vision chart. When the visual acuity value did not reach the threshold of 0.8 , the best-corrected visual acuity was measured using the Auto Kerato-Refractometer (KR-8800; TOPCON Corporation, Tokyo, Japan) and the pinhole test. Both eyes were examined separately. In this study, we used the best-corrected visual acuity of the better eye for further analysis. Visual acuity $>0.5$ was defined as good, and visual acuity $<0.5$ was defined as poor. This value $(0.5)$ represents the approximate lower $10 \%$ of visual acuity in the study participants as well as the cut-off value of visual impairment, according to other studies. ${ }^{12} 13$

\section{Assessment of muscle mass}

Whole-body muscle mass was measured using DXA with a fan-beam densitometer (Hologic, Bedford, MA, USA).
DXA is the most widely used and appropriate method for evaluating body composition; however, in Asians, DXA tends to overestimate the appendicular muscle mass because of higher adiposity in these populations. ${ }^{14}$

In this study, low muscle mass was defined as a value of appendicular skeletal muscle mass (ASM) divided by height squared $\left(\mathrm{kg} / \mathrm{m}^{2}\right)$, which was lower than the lowest quintile for the older population from the KNHANES survey $^{15}{ }^{16}$; the suggested cut-off value was $6.43 \mathrm{~kg} /$ $\mathrm{m}^{2}$. Height-adjusted methods can be more useful than weight-adjusted methods for identifying and characterising muscle mass in Asian populations.

\section{Statistical analysis}

All analyses used integrated weight values proposed by the Korea Centers for Disease Control and Prevention to represent the entire Korean population, including non-responders, considering the multistage probability sampling design of the KNHANES. Weight values were determined by the number of participants and research items of each survey year.

We used $\chi^{2}$ test for categorical variables and t-test for continuous variables in order to compare the characteristics between the good and poor vision groups. The results are presented as mean $\pm \mathrm{SE}$ and estimated proportions $\pm \mathrm{SE}$ for continuous and categorical variables, respectively. Multivariable logistic regression analysis was performed to examine the relationship between low muscle mass and visual acuity status after adjusting for covariates. The primary outcome variable was muscle mass status. Factors known to affect the reduction in muscle mass were adjusted in three steps. These factors included age, smoking status, ${ }^{17}$ frequency of alcohol consumption, ${ }^{18}$ physical activity, ${ }^{19}$ comorbidities (ie, myocardial infarction, stroke, hypertension and diabetes $)^{20}$ and socioeconomic status. ${ }^{21}$ The level of statistical significance was defined as $\mathrm{p}<0.05$. Data management and analysis were performed using SPSS V.20.0.

\section{Patient and public involvement}

Our study used data from KNHANES and KNHANESenrolled general Korean population. Thus, no patient was directly involved in our study.

\section{RESULTS}

\section{General characteristics of the participants}

The baseline characteristics of the study population are shown in table 1 . In this representative population, among 1733 older men older than 65 years, $10.1 \%$ had reduced visual acuity at values lower than 0.5 . Overall, the participants' mean age was 71.99 years. Participants in the poor vision group were older and less obese (lower body mass index and waist circumference) than those in the good vision group ( $<<0.001$ for both). Between the two groups, no significant differences in lifestyle, including smoking status, frequency of alcohol consumption and physical activity, were observed. There was significant 


\begin{tabular}{|c|c|c|c|}
\hline & $\begin{array}{l}\text { Visual acuity } \\
<0.5\end{array}$ & $\begin{array}{l}\text { Visual acuity } \\
\geq 0.5\end{array}$ & $P$ value \\
\hline Age & $76.43 \pm 0.50$ & $71.51 \pm 0.15$ & $<0.001$ \\
\hline Height (cm) & $162.88 \pm 0.42$ & $165.09 \pm 0.17$ & $<0.001$ \\
\hline Weight (kg) & $58.97 \pm 0.83$ & $63.34 \pm 0.32$ & $<0.001$ \\
\hline $\begin{array}{l}\text { Body mass index }(\mathrm{kg} / \\
\left.\mathrm{m}^{2}\right)\end{array}$ & $22.19 \pm 0.28$ & $23.19 \pm 0.10$ & $<0.001$ \\
\hline $\begin{array}{l}\text { Waist circumference } \\
(\mathrm{cm})\end{array}$ & $82.52 \pm 0.90$ & $84.94 \pm 0.330$ & $<0.001$ \\
\hline Smoking & & & 0.267 \\
\hline Never & $10.9(2.3)$ & $15.8(1.1)$ & \\
\hline Former & $61.3(3.9)$ & $57.6(1.5)$ & \\
\hline Current & $27.7(3.7)$ & $26.6(1.3)$ & \\
\hline Alcohol & & & 0.984 \\
\hline None & $13.1(3.1)$ & $13.7(1.0)$ & \\
\hline $\begin{array}{l}\text { Once a week or less } \\
\text { frequent }\end{array}$ & $76.7(3.6)$ & $76.3(1.3)$ & \\
\hline $\begin{array}{l}\text { More than twice a } \\
\text { week }\end{array}$ & $10.2(2.7)$ & $10.0(0.9)$ & \\
\hline Regular exercise & $90.4(2.7)$ & $88.1(1.0)$ & 0.464 \\
\hline \multicolumn{4}{|l|}{ Education } \\
\hline Elementary or lower & $73.8(4.0)$ & $48.8(1.7)$ & $<0.001$ \\
\hline Middle school & $10.8(2.6)$ & $19.1(1.3)$ & \\
\hline High school & $9.6(2.6)$ & $19.3(1.2)$ & \\
\hline College or higher & $5.8(2.1)$ & $12.8(1.3)$ & \\
\hline $\begin{array}{l}\text { Basic livelihood } \\
\text { security recipient }\end{array}$ & $5.0(1.6)$ & $4.4(0.7)$ & 0.713 \\
\hline Myocardiac infarction & $1.9(1.0)$ & $2.3(1.6)$ & 0.717 \\
\hline Stroke & $9.1(2.5)$ & $4.6(0.6)$ & 0.03 \\
\hline Hypertension & $38.1(4.3)$ & $39.8(1.5)$ & 0.718 \\
\hline Diabetes & $19.8(3.4)$ & $14.0(0.9)$ & 0.071 \\
\hline
\end{tabular}

Data are presented as mean \pm SE or estimated \% (SE).

Values were calculated using a t-test and $\chi^{2}$ test.

All analyses used integrated weight values.

difference in education level between the two groups $(p<0.001)$, but there was no significant difference in the proportion of national basic livelihood recipients. Participants who had a stroke were more common in the poor vision group than in the good vision group $(\mathrm{p}=0.030)$, but the prevalence of other comorbidities such as myocardial infarction, hypertension and diabetes were not significantly different between the two groups.

\section{Muscle mass according to visual acuity}

After adjusting for age, the poor vision group showed lower ASM than the good vision group (19.54 \pm 0.09 vs $18.81 \pm 0.23 ; \mathrm{p}=0.003)$. Height-adjusted ASM values were $7.16 \pm 0.03$ and $7.00 \pm 0.07 \mathrm{~kg} / \mathrm{m}^{2}$ in the good and poor vision groups, respectively, after adjusting for age
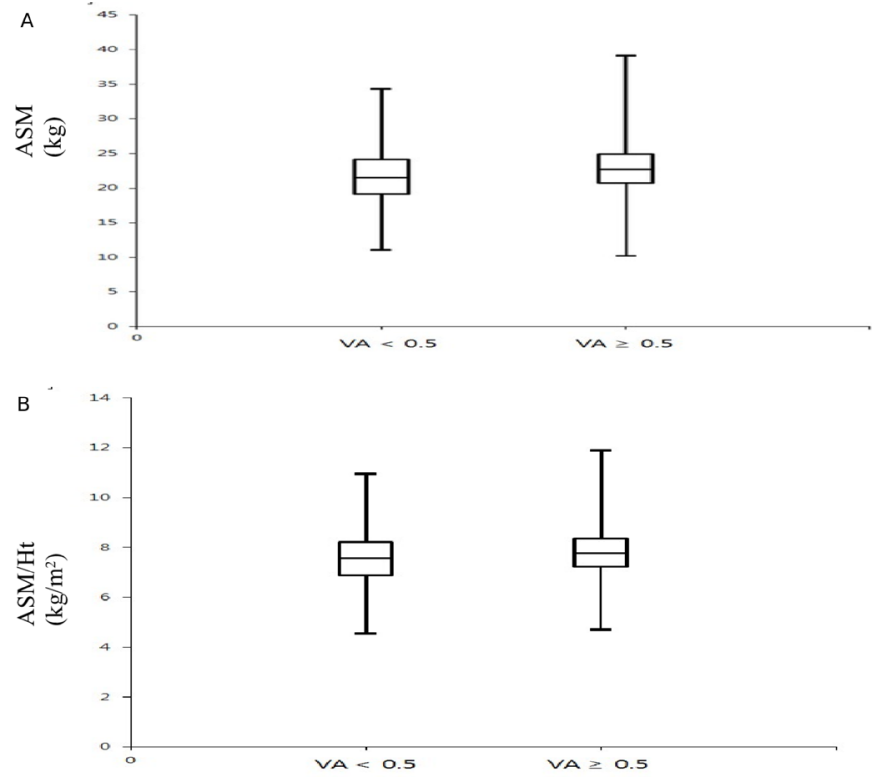

Figure 1 Comparison of muscle mass according to the visual acuity status after adjusting for age: (A) ASM and (B) $\mathrm{ASM} / \mathrm{Ht}$. Data were calculated using the complex sample general linear model. ASM, appendicular skeletal muscle mass; Ht, height.

( $\mathrm{p}=0.042$ ). Our study criterion for low muscle mass (height-adjusted ASM $<6.43 \mathrm{~kg} / \mathrm{m}^{2}$ ) was met by $16.40 \%$ and $34.70 \%$ of participants in the good and poor vision groups, respectively. Figure 1A,B shows the muscle mass values of participants according to their visual acuity status.

\section{Effects of impaired visual acuity on low muscle mass}

Complex sample logistic regression analysis was performed to evaluate the independent association between impaired visual acuity and low muscle mass in older men. The results of this analysis are presented in table 2. After adjusting for age, the OR for low muscle mass was 1.73 (95\% CI 1.12 to 2.67; $\mathrm{p}=0.014$; model 1 ). Similarly, after further adjusting for health behaviours such as smoking status, alcohol consumption and frequency of physical activity, impaired visual acuity in the older men carried a 1.71-fold increased risk of low muscle mass relative to good vision (95\% CI 1.03 to 2.84; $\mathrm{p}=0.039$; model 2). Univariate analysis of socioeconomic status including the level of education and the status of national basic livelihood recipient revealed a difference in the incidence of stroke between the two groups, which was further adjusted in model 3; even after further adjustments, this trend was maintained (model 3: OR=1.60; 95\% CI 1.02 to $2.50 ; \mathrm{p}=0.040)$.

\section{DISCUSSION}

In this representative population-based study, we showed that the prevalence of reduced visual acuity, which was defined as best-corrected visual acuity of the better eye $<0.5$, was $10.1 \%$ in older men aged 65 years or older. Our 
Table 2 Association between low muscle mass and reduced visual acuity relative to good visual acuity

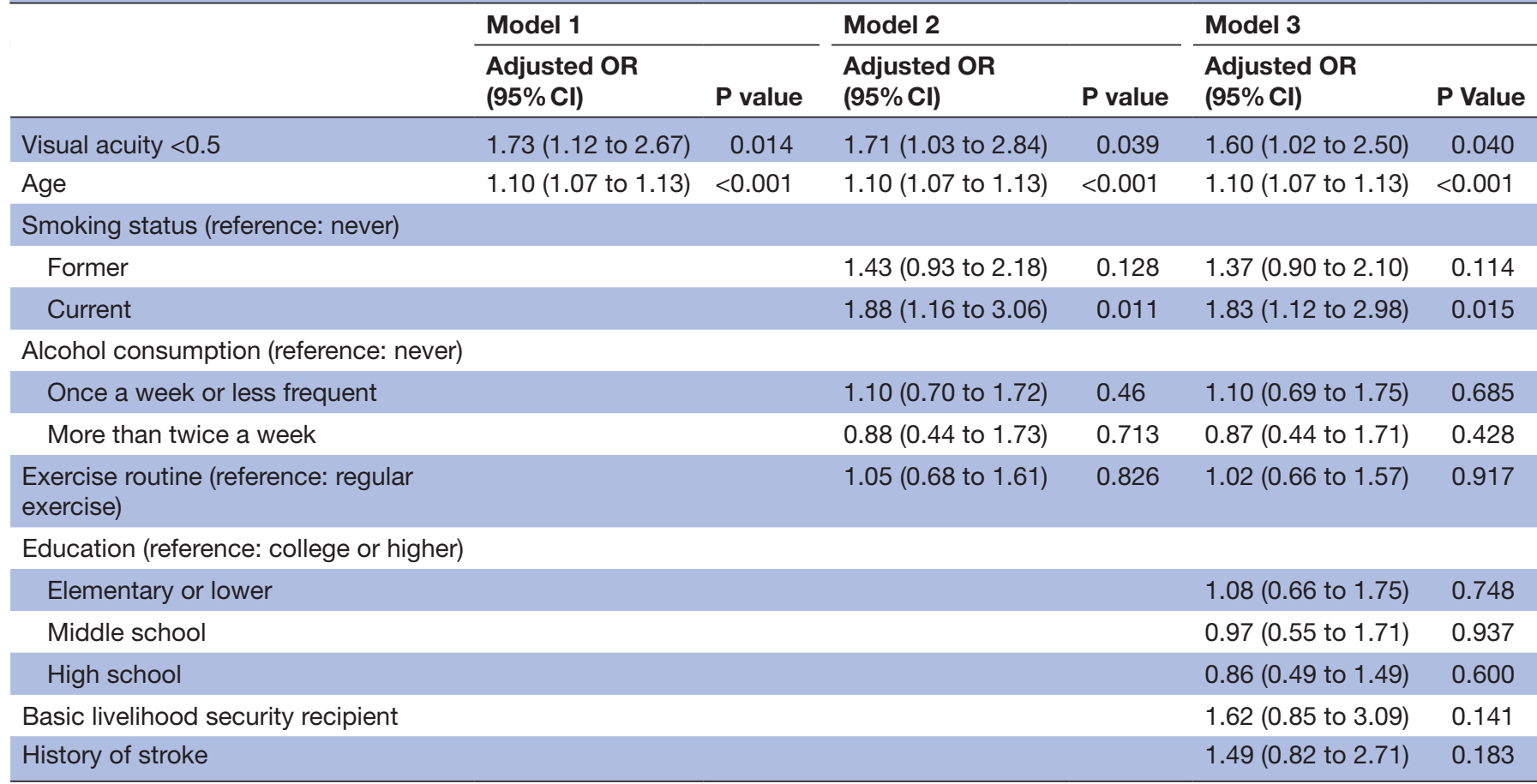

Values were calculated using a multivariable logistic regression analysis.

All analyses used integrated weight values.

Model 1: adjusted for age. Model 2: adjusted for age, smoking status, alcohol consumption and frequency of physical activity. Model 3 : adjusted for age, smoking status, alcohol consumption, frequency of physical activity, educational level, the status of basic livelihood security recipient and history of stroke.

study indicated that vision is closely linked to muscle mass and that poor vision is related with low muscle mass in older men, thus validating our hypothesis.

The mechanism by which vision and muscle mass are related is not yet clear. Vision also has an important role in balance control. Visual acuity provides the nervous system with updated information on the position and movements of the body in relation to one another and to the environment. ${ }^{22}$ According to a previous study that evaluated participants with central field defects followed by age-related macular degeneration, vision contributed to postural stabilisation as participants with reduced vision had difficulties in maintaining their posture compared with participants with normal vision. ${ }^{23}$ The ability to walk without falling depends on the integration of multiple components that interface balance and gait. Older population who have poor vision can develop compromised gait, and their gait velocity is reduced. ${ }^{24}$ Participants with age-related acute maculopathy walked slower and exhibited longer swing time with high levels of caution than healthy controls. ${ }^{25}$ Further, changes in balance and gait can negatively affect an older adult's level of activity, compounding the cyclic nature of physical decline. ${ }^{26}$

A previous cohort study demonstrated that blurred vision had an influence on functional status with wellbeing (measured using a questionnaire on limitations of physical function), feeling of interference with social activities and nervousness along with a depressed mood. Particularly, adults with blurred vision experience role limitations because of physical health problems. ${ }^{27}$ Older population with poor vision can have difficulty with social networking and experience a decrease in leisure activities. Consequently, the less physically active an individual becomes, the greater the likelihood that muscle mass gradually becomes further compromised.

During the ageing process, the crystalline lens loses its elasticity and normal accommodating power; thus, it cannot adequately focus on objects within reading distance. One of the mechanisms behind presbyopia is the functional failure of ciliary smooth muscles, which play a role in increasing the curvature of the lens and help in accommodation. ${ }^{28}$ Further research is needed to clarify if muscle mass loss also affects the eye muscles, thereby affecting eyesight.

The present study had a couple of limitations. Along with muscle mass, muscle strength measured using grip strength and physical functions such as gait speed are important in the assessment of older population health, and these variables were not assessed in this study. However, in many studies, muscle mass is shown to be correlated with muscle function, and muscle mass is a key factor in assessments of older populations. ${ }^{29}$ Another limitation is related to the items used in the evaluation of visual function. Indeed, visual acuity is an important 
indicator of visual function; however, the visual field can also be considered, and visual efficiency, which is composed of visual acuity, the visual field and eye movement, is a good indicator of visual function. ${ }^{30}$ In conclusion, the results of this study indicate that poor vision is closely associated with reduced muscle mass, and poor vision might be an indicator of low muscle mass.

Contributors JHM, YHO, MHK and HJK designed this study and wrote the manuscript. JHM obtained funding. JHM and YHO analysed the data. All authors have full access to all data (including statistical reports and tables) used in the study and take responsibility for the integrity of the data and accuracy of the data analysis.

Funding This work was supported by a research grant from Jeju National University Hospital in 2017 (2017-33).

Competing interests None declared.

Patient consent for publication Obtained.

Ethics approval All procedures performed in studies involving human participants were in accordance with the ethical standards of the institutional review board of the Korea Centers for Disease Control and Prevention (reference numbers 2008-04EXP-01-C, 2009-01CON-03-2C, 2010-02C0N-21-C and 2011-02CON06-C) and with the 1964 Helsinki Declaration and its later amendments or comparable ethical standards. The present study did not require additional review and approval because the KNHANES dataset is publicly available.

Provenance and peer review Not commissioned; externally peer reviewed. Data availability statement Data are available in a public, open access repository. Open access This is an open access article distributed in accordance with the Creative Commons Attribution Non Commercial (CC BY-NC 4.0) license, which permits others to distribute, remix, adapt, build upon this work non-commercially, and license their derivative works on different terms, provided the original work is properly cited, appropriate credit is given, any changes made indicated, and the use is non-commercial. See: http://creativecommons.org/licenses/by-nc/4.0/.

ORCID iDs

Ji Hyun Moon http://orcid.org/0000-0001-6788-7521

Hyeon Ju Kim http://orcid.org/0000-0002-9103-3275

\section{REFERENCES}

1 Kang MJ, Rim TH, Kim SS, et al. Visual acuity and falls in South Korea: Korean National health and nutrition examination survey 2008-2012. J Korean Ophthalmol Soc 2016;57:1451-9.

2 Coleman AL, Stone K, Ewing SK, et al. Higher risk of multiple falls among elderly women who lose visual acuity. Ophthalmology 2004;111:857-62.

3 Araki A, Nakano T, Oba K, et al. Low well-being, cognitive impairment and visual impairment associated with functional disabilities in elderly Japanese patients with diabetes mellitus. Geriatr Gerontol Int 2004:4:15-24.

4 Klein BEK, Klein R, Knudtson MD, et al. Relationship of measures of frailty to visual function: the Beaver dam eye study. Trans Am Ophthalmol Soc 2003;101:191-6.

5 Wu Y, Pang Z, Zhang D, et al. A cross-sectional analysis of age and sex patterns in grip strength, tooth loss, near vision and hearing levels in Chinese aged 50-74 years. Arch Gerontol Geriatr 2012;54:e213-20.

6 Horvat M, Ray C, Croce R, et al. A comparison of isokinetic muscle strength and power in visually impaired and sighted individuals. Isokinet Exerc Sci 2004;12:179-83.

7 Reed RL, Pearlmutter L, Yochum K, et al. The relationship between muscle mass and muscle strength in the elderly. $J$ Am Geriatr Soc 1991;39:555-61.
8 Cruz-Jentoft AJ, Landi F, Topinková E, et al. Understanding sarcopenia as a geriatric syndrome. Curr Opin Clin Nutr Metab Care 2010;13:1-7.

$9 \mathrm{Kim} \mathrm{H}-\mathrm{J}$, Yoon DH, So B, et al. Practical application of resistance exercise for prevention of sarcopenia. J Korean Geriatr Soc 2015;19:205-17.

10 Yang W, Gui Q, Chen L, et al. Associations between dietary protein and vitamin intake and the physical functioning of older adults with sarcopenia. Eur Geriatr Med 2018;9:311-20.

11 Kweon S, Kim Y, Jang M-jin, et al. Data resource profile: the Korea National health and nutrition examination survey (KNHANES). Int $J$ Epidemiol 2014;43:69-77.

12 Swenor BK, Simonsick EM, Ferrucci L, et al. Visual impairment and incident mobility limitations: the health, aging and body composition study. J Am Geriatr Soc 2015;63:46-54.

13 Salive ME, Guralnik J, Glynn RJ, et al. Association of visual impairment with mobility and physical function. J Am Geriatr Soc 1994;42:287-92.

14 Chen L-K, Liu L-K, Woo J, et al. Sarcopenia in Asia: consensus report of the Asian Working group for sarcopenia. J Am Med Dir Assoc 2014;15:95-101.

15 Chen L-K, Lee W-J, Peng L-N, et al. Recent advances in sarcopenia research in Asia: 2016 update from the Asian Working group for sarcopenia. J Am Med Dir Assoc 2016;17:767.e1-e7.

$16 \mathrm{Kwon} \mathrm{H}-\mathrm{J}, \mathrm{Ha} \mathrm{Y}-\mathrm{C}$, Park $\mathrm{H}-\mathrm{M}$. The reference value of skeletal muscle mass index for defining the sarcopenia of women in Korea. $J$ Bone Metab 2015;22:71-5.

17 Rom O, Kaisari S, Aizenbud D, et al. Sarcopenia and smoking: a possible cellular model of cigarette smoke effects on muscle protein breakdown. Ann N Y Acad Sci 2012;1259:47-53.

18 Thapaliya S, Runkana A, McMullen MR, et al. Alcohol-Induced autophagy contributes to loss in skeletal muscle mass. Autophagy 2014;10:677-90.

19 Shin HE, Kwak SE, Lee J-H, et al. Exercise, the gut microbiome, and frailty. Ann Geriatr Med Res 2019;23:105-14.

20 Chen L, Nelson DR, Zhao Y, et al. Relationship between muscle mass and muscle strength, and the impact of comorbidities: a populationbased, cross-sectional study of older adults in the United States. BMC Geriatr 2013;13:74.

21 Dorosty A, Arero G, Chamar M, et al. Prevalence of sarcopenia and its association with socioeconomic status among the elderly in Tehran. Ethiop J Health Sci 2016:26:389-96.

22 Kulmala J, Viljanen A, Sipilä S, et al. Poor vision accompanied with other sensory impairments as a predictor of falls in older women. Age Ageing 2009;38:162-7.

23 Turano KA, Dagnelie G, Herdman SJ. Visual stabilization of posture in persons with central visual field loss. Invest Ophthalmol Vis Sci 1996;37:1483-91.

24 Riley PO, DellaCroce U, Kerrigan DC. Effect of age on lower extremity joint moment contributions to gait speed. Gait Posture 2001;14:264-70.

25 Spaulding SJ, Patla AE, Elliott DB, et al. Waterloo vision and mobility study: gait adaptations to altered surfaces in individuals with agerelated maculopathy. Optom Vis Sci 1994;71:770-7.

26 Ray CT, Wolf SL. Review of intrinsic factors related to fall risk in individuals with visual impairments. $J$ Rehabil Res Dev 2008;45:1117-24.

27 Donoghue OA, Ryan H, Duggan E, et al. Relationship between fear of falling and mobility varies with visual function among older adults. Geriatr Gerontol Int 2014;14:827-36.

28 Lee YS. Presbyopic contact lens fitting. In: Kim MG, Kim TJ, Park YG, eds. Contact lens: principles and practice. Seouk: Naeoehaksul, 2007: 13-141.

29 Ramírez-Fuentes C, Mínguez-Blasco P, Ostiz F, et al. Ultrasound assessment of rectus femoris muscle in rehabilitation patients with chronic obstructive pulmonary disease screened for sarcopenia: correlation of muscle size with quadriceps strength and fat-free mass. Eur Geriatr Med 2019;10:89-97.

30 McBride ED. Injury of the eye. In: Disability evaluation and principles of treatment of compensable injuries. 6th edn. Philadelphia: Lippincott, 1996. 